\title{
Optimized model for rapid battery charging using constant current constant voltage protocol
}

Emeruwa, $\mathrm{C}^{*}$ and Edem, M. E.

Department of Physics, Federal University Otuoke, Nigeria.

GSC Advanced Engineering and Technology, 2022, 02(01), 062-068

Publication history: Received on 01 January 2022; revised on 03 Februay 2022; accepted on 05 Februay 2022

Article DOI: https://doi.org/10.30574/gscaet.2021.2.1.0025

\begin{abstract}
This research, which aims to find the best constant current, constant voltage parameters for charging a battery in the quickest time possible, subjects battery cells to varied charging and discharge rates in order to determine their rate capabilities. Cycling the cells using constant current, constant voltage charge in 60 minutes and 90 minutes discharge for 400 cycles examines the effects of the charging current Charge Rate and the voltage limit for the constant voltage on the battery's discharge capacity. The results obtained showed that $1.3 \mathrm{C}$-rate and 4.3V voltage limit produced the utmost discharge capacity and cycle life. During the cycling period, the cell temperature was under $39^{\circ} \mathrm{C}$ with a capacity loss after 400 cycles of $8 \%$. A 3 percent capacity gain was seen after charging the batteries using the cccv methodology for 180 minutes and then discharging them for 120 minutes. This low capacity loss after 400 cycles suggests that an optimal charging model employing the cccv protocol is possible.
\end{abstract}

Keywords: Battery; Cells; Constant Current; Constant Voltage; C-Rate; Discharge Capacity

\section{Introduction}

The charging time is a major issue for all Lithium Ion Battery applications, particularly mobile electronics and electric mobility [1]. Rapid charging will undoubtedly benefit the future battery market. Every equipment or machine that runs on batteries has a usage time that is proportional to the amount of stored electrical energy within the battery's cells. $[2,3]$. The amount of stored electrical energy stored in the battery cells is the product of the energy density multiplied by the volume and mass of the entire battery system. There has been a notable increase in the energy density of industrial batteries in the last one decade, presently we have energy density of batteries at 260Wh/kg and 700Wh/I [4]. For battery powered electric vehicles (BEV) to fully gain acceptance, the charging time should be similar to the time required to refill the tank of an internal combustion engine vehicles which is typically about 10 mins while ensuring a driving range of not less than $500 \mathrm{~km}$.

Rapid charging using Constant Current Constant Voltage (CCCV) protocol has been proposed to improve the charging time of batteries to at least $60 \mathrm{mins}$ for $100 \%$ gain in the state of charge. CCCV protocol is about applying a constant charging current ( $\mathrm{C}$-rate) up to an upper voltage limit $\left(\mathrm{V}_{\lim }\right)$ and applying a constant voltage of $\mathrm{V}_{\text {lim }}$ till a current limit is achieved. The challenge faced when attempting to reduce the charging time of batteries to $60 \mathrm{mins}$ and below is active material degradation, Lithium metal plating at the anode and temperature rise [5,6,7]. In this work the CCCV protocol will be used to attempt reducing the charging time of LIBs while maintaining good safety and long cycle life. Rapid charging using CCCV protocol involves two distinctive phases, the CC phase with time $t_{c c}$ and the CV phase with time $t_{c v}$. This gives the total charging time $\mathrm{T}_{\mathrm{c}}$ as

$$
T_{c}=t_{c c}+t_{c v}
$$

\footnotetext{
${ }^{*}$ Corresponding author: Emeruwa C

Department of Physics, Federal University Otuoke, Nigeria. 


\subsection{Cell conditioning and rate capacity profiling}

Two identical LIB batteries rated $3650 \mathrm{mAh}$ are employed in this study. All tests are carried out at room temperature $\left(27 \pm 2^{\circ} \mathrm{C}\right)$. Charging and discharging was done repeatedly for five times using slow rate CCCV. A charge current of $740 \mathrm{~mA}$ to $V_{\text {lim }}$ of $4.4 \mathrm{~V}$ was used for charging for $20 \mathrm{mins}$ while a discharge current of $740 \mathrm{~mA}$ to $2.5 \mathrm{~V}$ was used for discharging. At the end of the 5 cycles, a stabilized discharge capacity of $3600 \mathrm{mAh}$ was achieved. This discharge capacity is the battery cell's nominal capacity.

Before quick charging, rate capacity test is done to ascertain if the battery cells can withstand high discharge currents. The battery cells are subjected to CCCV protocol charging at C-rate of C/3 to 4.4V; after which it was also subjected to a discharge at increasing C-rates of $\mathrm{C} / 5, \mathrm{C} / 2, \mathrm{C}, 2 \mathrm{C}, 2.7 \mathrm{C}$ and $3.8 \mathrm{C}$ to $2.5 \mathrm{~V}$. The average voltage (E) and discharge capacity $\left(Q^{\text {dis }}\right)$ were then ascertained. From the discharge data, the average voltage, energy density $W_{d}$ and power density $P_{d}$ are calculated as follows

$$
\begin{gathered}
E=\int_{0}^{Q^{d i s}} \frac{E(q) d q}{Q^{d i s}} \\
W_{d}=\frac{Q^{d i s} x\langle E\rangle}{m}(W h / k g) \\
P_{d}=\frac{I_{d} x\langle E\rangle}{m}(W / k g)
\end{gathered}
$$

Where $E(q)$ is the discharge profile

$\mathrm{m}$ is the cell's mass

$I_{d}$ is the discharge current

\section{CCCV protocol charging and cycle capacity}

The battery cells are charged using the CCCV protocol for 60mins with varying charge rates and voltage limits. The corresponding $\mathrm{t}_{\mathrm{cc}}$ and $\mathrm{t}_{\mathrm{cv}}$ for each of the $\mathrm{C}$-rate and $\mathrm{V}_{\mathrm{lim}}$ were noted. Similarly, the charge gained during the CC $\left(Q_{c v}^{c h}\right)$ steps were also calculated while the system temperature was continuously monitored through the whole process. The respective sets of $\mathrm{C}$-rate and $\mathrm{V}_{\mathrm{lim}}$ used are $1.2 \mathrm{C} / 4.25 \mathrm{~V}, 1.3 \mathrm{C} / 4.3 \mathrm{~V}$ and $1.4 \mathrm{C} / 4.35 \mathrm{~V}$.

After charging the battery for $60 \mathrm{mins}$, the cell is rested for a period of $30 \mathrm{mins}$ before discharging. The discharging is done within $90 \mathrm{mins}$ period at a $0.65 \mathrm{C}$-rate. After the discharge process, another rest period of $30 \mathrm{mins}$ is observed before the next cycle commences. After 400 complete cycles, the C-rate and $V_{\text {lim }}$ combination with the best discharge capacity and lowest capacity fade is identified.

\section{Results and discussion}

The various discharge data such as Power Density $\mathrm{P}_{\mathrm{d}}$, Energy Density $\mathrm{W}_{\mathrm{d}}$, Discharge Capacity $Q^{\text {dis }}$ and Average Discharge Voltage E are shown in table 1.

Table 1 Cell Performance during Discharge at Different C-Rates

\begin{tabular}{|l|c|c|c|c|c|}
\hline \multicolumn{1}{|c|}{ C-rate } & $\mathbf{C} / \mathbf{5}$ & $\mathbf{C} / \mathbf{2}$ & $\mathbf{C}$ & $\mathbf{2 C}$ & $\mathbf{2 . 7 C}$ \\
\hline$<\mathrm{E}>(\mathrm{V})$ & 3.9 & 3.8 & 3.6 & 3.4 & 3.3 \\
\hline$Q^{\text {dis }}(\mathrm{mAh})$ & 3697 & 3681 & 3659 & 3567 & 3609 \\
\hline$P_{d}(\mathrm{~W} / \mathrm{kg})$ & 51.4 & 124.9 & 238.9 & 453.1 & 591.7 \\
\hline$W_{d}(\mathrm{Wh} / \mathrm{kg})$ & 255.1 & 247.5 & 236.2 & 217.2 & 213.5 \\
\hline
\end{tabular}

From the table, it is seen that the energy density was satisfying at all the discharge rates. It dropped from $260 \mathrm{Wh} / \mathrm{kg}$ at $\mathrm{C} / 5$ rate to $219 \mathrm{Wh} / \mathrm{kg}$ at $2.7 \mathrm{C}$-rate which amounts to about $16 \%$ drop. On the other hand, the Power density increased 
from $52.4 \mathrm{~W} / \mathrm{kg}$ at $\mathrm{C} / 5$ rate to $593.2 \mathrm{~W} / \mathrm{kg}$ at $2.7 \mathrm{C}$-rate. A low average cell polarization is also noticed as the difference between average discharge voltage $\mathrm{E}$ at $5 \mathrm{C}$-rate and $2.7 \mathrm{C}$-rate is only $13.2 \%$. It was also noticed that the temperature raised above $55^{\circ} \mathrm{C}$ when discharged at $3.8 \mathrm{C}$-rate after $180 \mathrm{mins}$ of charge. This situation forced the test to discontinue due to safety reasons. Fig 1 shows the voltage-time profiles during the charging using CCCV protocol at C/3-rate to $\mathrm{V}_{\text {lim }}$ $4.4 \mathrm{~V}$ and during the discharge with different C-rates, while Fig 2. shows the voltage-capacity profile at different C-rate during discharge. Fig 3. is the Ragone plot from table 1.

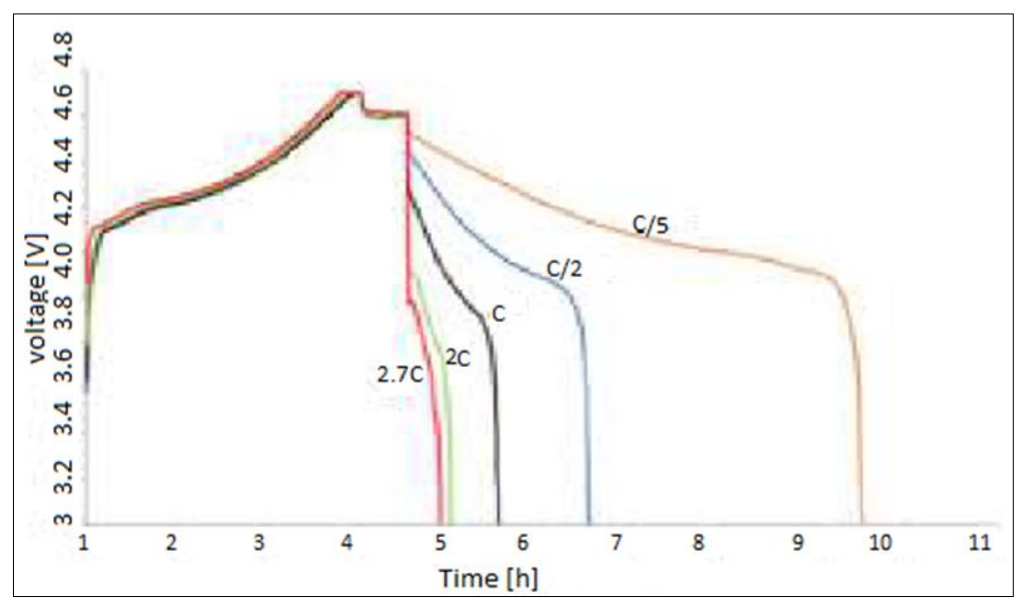

Figure 1 Voltage - Time Profile during CCCV Charge In 180min and Discharge at Different C-rates

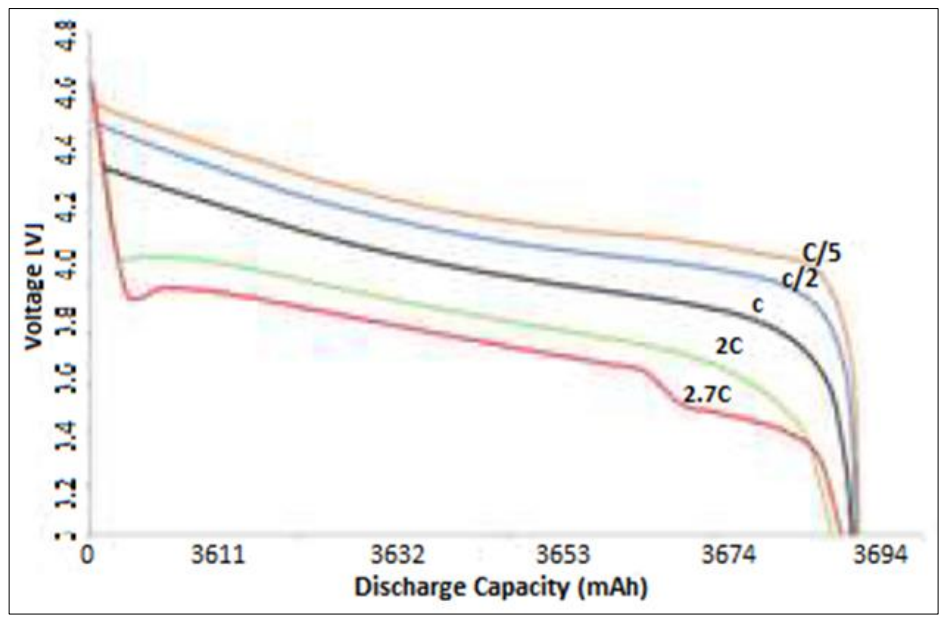

Figure 2 Voltage - Discharge Capacity Profile at Different C-rates

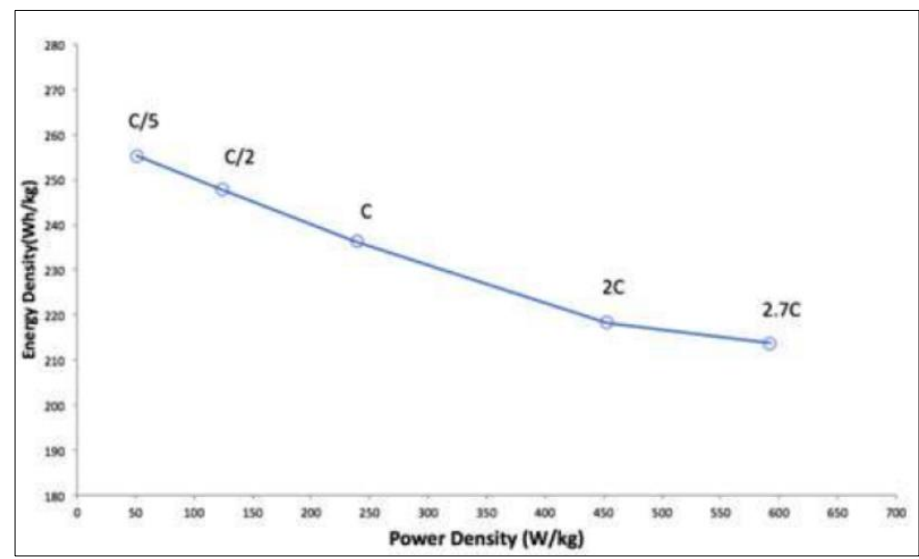

Figure 3 Ragone Plot Achieved at Different C-rates 
The profile of CCCV charge and CC discharge is shown in Fig.4. It shows the current and voltage profile during 60mins charging using CCCV protocol with $30 \mathrm{mins}$ break followed by a $90 \mathrm{mins}$ discharge at C/1.5 rate and voltage limit $4.25 \mathrm{~V}$. Similarly the charge profile at $1.2 \mathrm{C}, 1.3 \mathrm{C}$ and $1.4 \mathrm{C}$ rates with voltage limits of $4.3 \mathrm{~V}, 4.35 \mathrm{~V}$ and $4.4 \mathrm{~V}$ are shown in figures 5,6 and 7 respectively with a total charging time $t_{c h}$ of 60 mins across board.

When the $\mathrm{V}_{\text {lim }}$ of $4.4 \mathrm{~V}$ is used at any C-rate, a high cell polarization is seen which generates much heat and hastens electrode and electrolyte material degradation. Thus for long cycle life, $\mathrm{V}_{\text {lim }}$ values must be kept below $4.4 \mathrm{~V}$. The comprehensive CCCV charge and CC discharge data are shown in Table2 while Fig.8 shows a 3D plot of the effects of Crate and $\mathrm{V}_{\text {lim }}$ on the discharge capacity. Maximum discharge capacity is reached at $4.35 \mathrm{~V}$ for both $1.3 \mathrm{C}$-rate and $1.4 \mathrm{C}$ rate while it is $4.4 \mathrm{~V}$ for $1.2 \mathrm{C}$-rate.

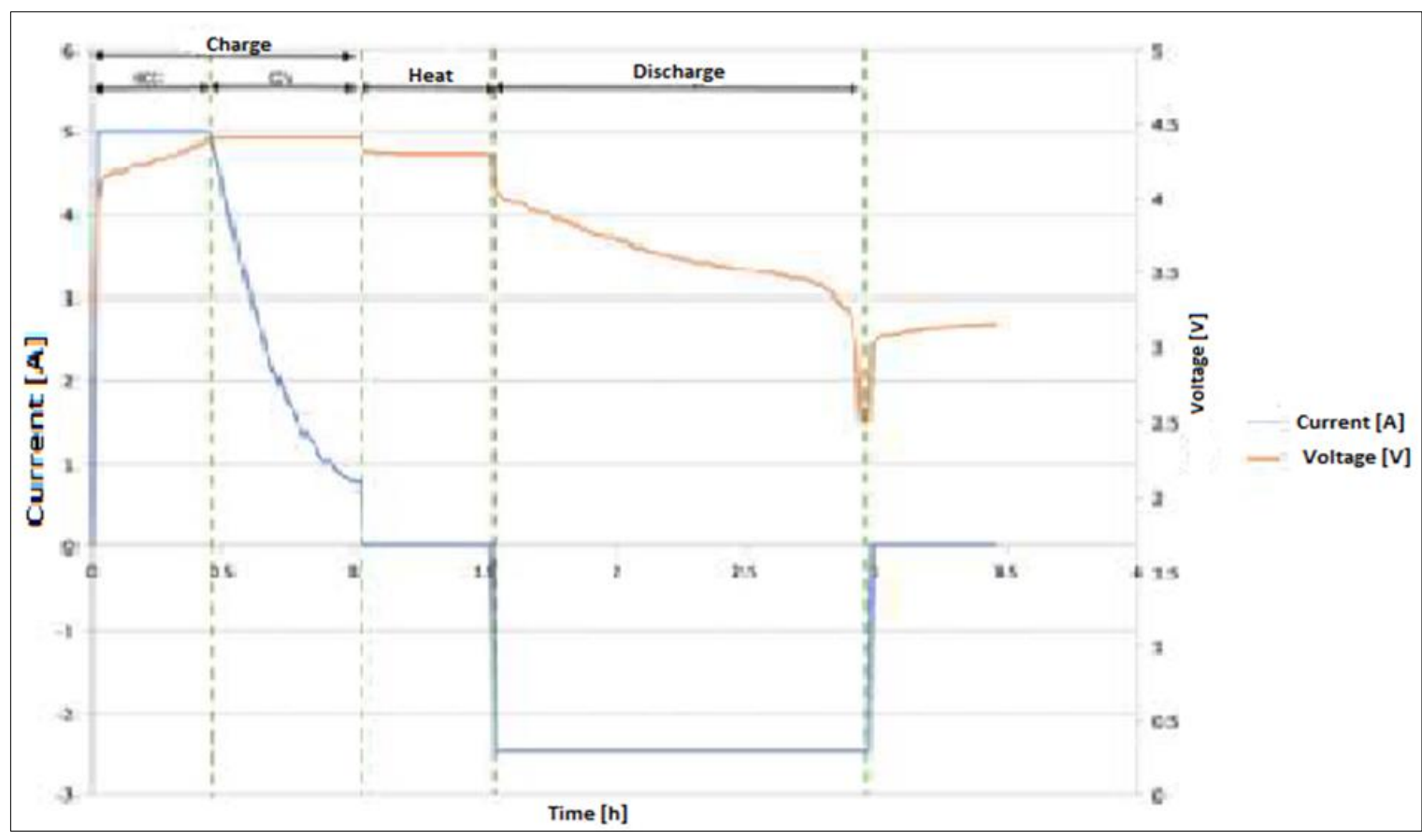

Figure 4 Current and Voltage Profiles during CCCV Charge in 60mins and Discharge in 90mins (with a rest period between Charge and Discharge)

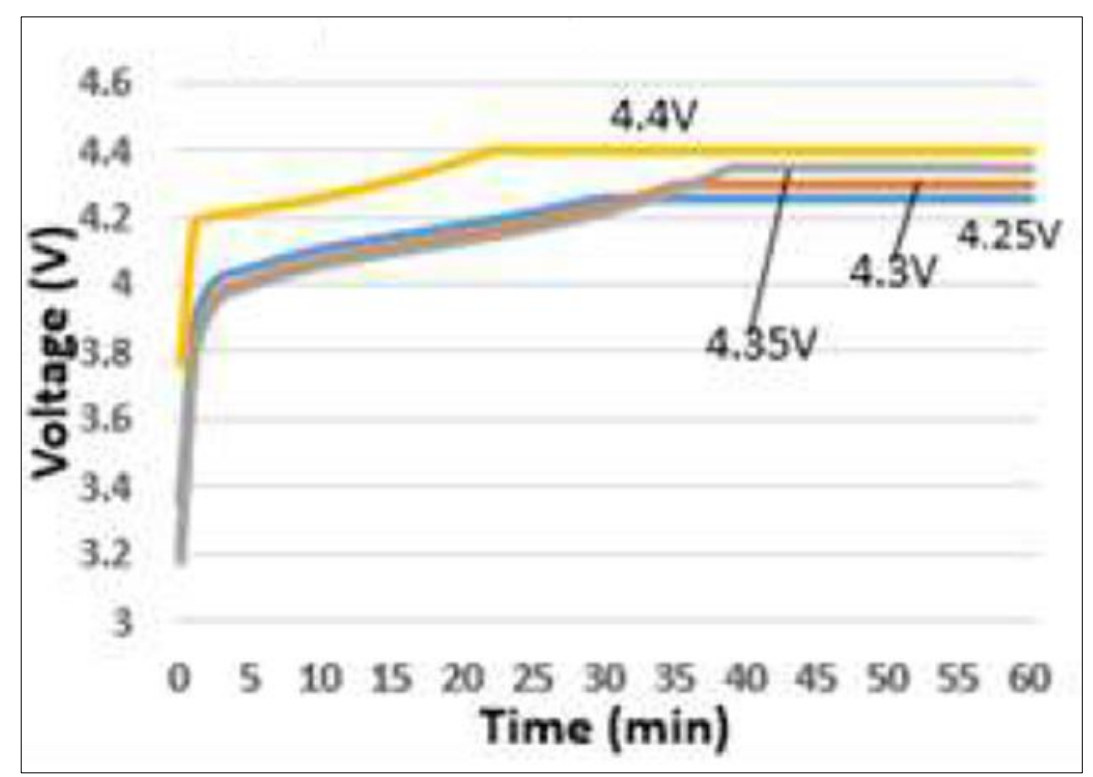

Figure 5 60mins CCCV Charge Profile with $\mathrm{V}_{\text {lim }}$ of 4.25V, 4.30V, 4.35V and 4.4V with C-rate of 1.2C 


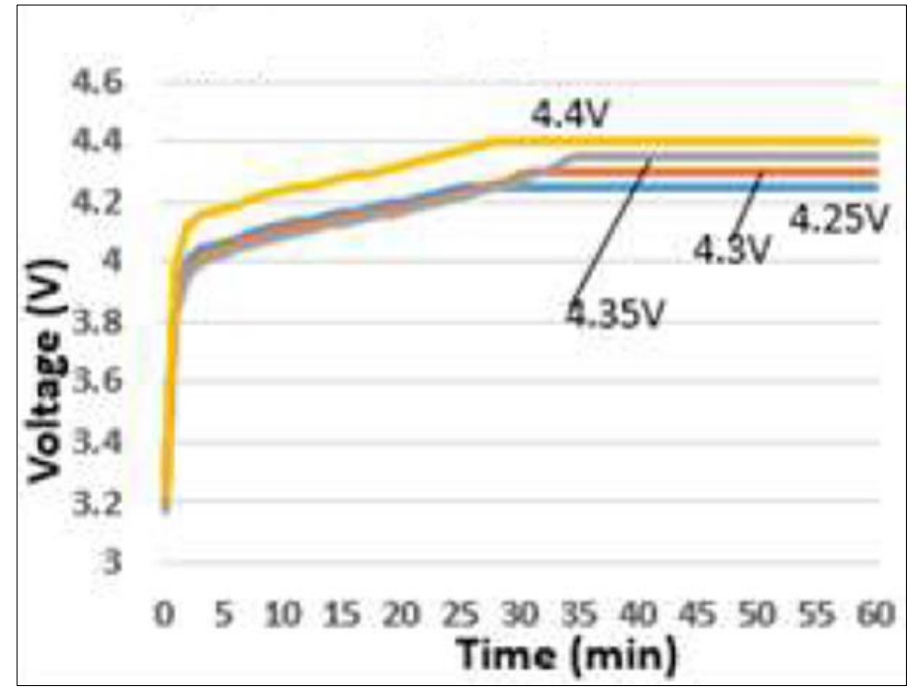

Figure 6 60mins CCCV Charge Profile with $\mathrm{V}_{\text {lim }}$ of 4.25V, 4.30V, 4.35V and 4.4V with C-rate of 1.3C

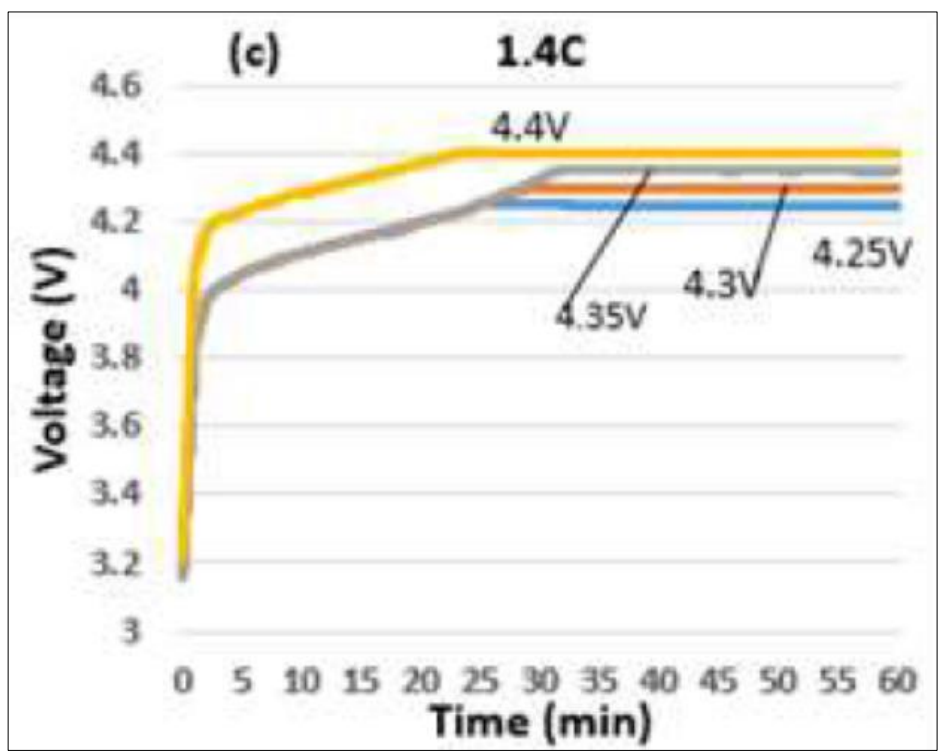

Figure $760 \mathrm{mins}$ CCCV Charge Profile with $\mathrm{V}_{\text {lim }}$ of 4.25V, 4.30V, 4.35V and 4.4V with C-rate of $1.4 \mathrm{C}$

Table 2 Charge and Discharge Performance during 60mins CCCV Charge and 0.6 C-rate Discharge

\begin{tabular}{|c|c|c|c|c|c|c|c|c|c|c|c|c|c|c|}
\hline \multirow{2}{*}{\multicolumn{3}{|c|}{$\begin{array}{r}\text { C-Rate } \\
V_{\text {lim of CV (V) }}\end{array}$}} & \multicolumn{4}{|c|}{1.2} & \multicolumn{4}{|c|}{1.3} & \multicolumn{4}{|c|}{1.4} \\
\hline & & & 4.25 & 4.3 & 4.35 & 4.4 & 4.25 & 4.3 & 4.35 & 4.4 & 4.25 & 4.3 & 4.35 & 4.4 \\
\hline \multirow{7}{*}{ Charge } & $\mathrm{CC}$ & $t_{c c}(\min )$ & 29 & 34 & 38 & 21 & 25 & 31 & 35 & 27 & 25 & 28 & 33 & 24 \\
\hline & & $Q_{c c}^{c h}(m A h)$ & 2119 & 2471 & 2754 & 1549 & 1988 & 2372 & 2677 & 2136 & 2059 & 2388 & 2637 & 1975 \\
\hline & & $\%$ of norminal & 65.2 & 72.1 & 77.1 & 54.4 & 61.3 & 68.5 & 74.4 & 61.3 & 61.4 & 68.9 & 73.5 & 54.9 \\
\hline & $\mathrm{CV}$ & $t_{c c}(\min )$ & 29 & 24 & 20 & 38 & 33 & 29 & 24 & 32 & 34 & 31 & 27 & 37 \\
\hline & & $Q_{c v}^{c h}(m A h)$ & 1082 & 907 & 772 & 1248 & 1265 & 1048 & 898 & 1355 & 1257 & 1081 & 970 & 1551 \\
\hline & & $\%$ of $Q^{c h}$ & 32.8 & 27.9 & 20.9 & 44.8 & 37.8 & 31.0 & 25.5 & 37.6 & 36.6 & 30.5 & 25.8 & 43.2 \\
\hline & Total & $Q^{c h}(m A h)$ & 3200 & 3379 & 3526 & 2799 & 3253 & 3420 & 3576 & 3491 & 3318 & 3471 & 3602 & 3524 \\
\hline
\end{tabular}




\begin{tabular}{|l|l|l|l|l|l|l|l|l|l|l|l|l|l|l|}
\hline & \% of norminal & 87.9 & 92.7 & 96.7 & 76.6 & 91.1 & 94.8 & 99.3 & 95.7 & 92.3 & 96.6 & 99.2 & 96.8 \\
\hline \multirow{2}{*}{ Discharge } & $Q^{\text {dis }}(m A h)$ & 3214 & 3378 & 3522 & 3660 & 3251 & 3422 & 3571 & 3491 & 3314 & 3468 & 3601 & 3525 \\
& \% of norminal & 86.8 & 92.4 & 95.3 & 101.2 & 88.6 & 93.7 & 98.0 & 94.7 & 90.1 & 93.9 & 99.0 & 96.1 \\
\hline
\end{tabular}

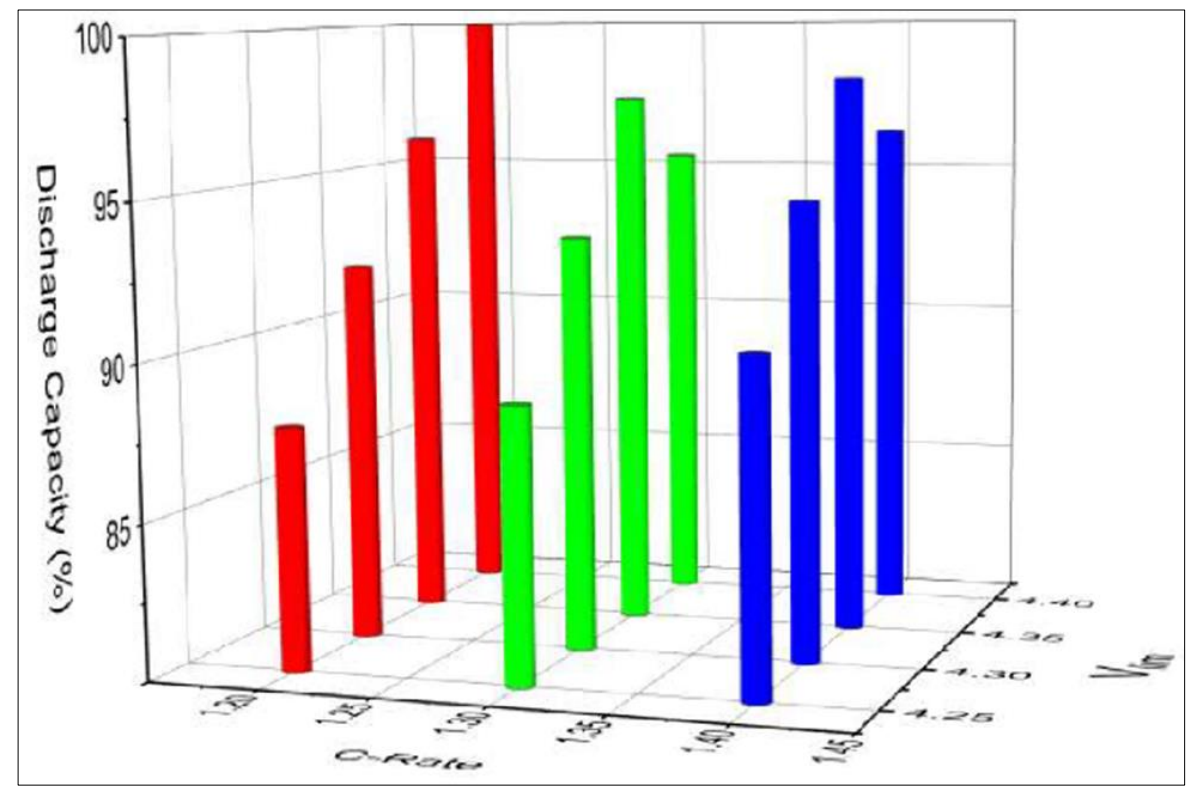

Figure 8 3D Plot of C-rate, $\mathrm{V}_{\mathrm{lim}}$ and Discharge Capacity Percentage during 60mins CCCV Charging

The initial cycle life tests showed that when the $\mathrm{V}_{\text {lim }}$ was $4.4 \mathrm{~V}$, capacity fading was high during cycling when compared to a $V_{\text {lim }}$ of $4.35 \mathrm{~V}$. This high fading capacity corresponds with other studies on performance degradation rate $[1,8,9]$. In line with this, $1.4 \mathrm{C}$-rate and $4.35 \mathrm{~V} \mathrm{~V}_{\text {lim }}$ was selected for long cycle test due to the good trade-off between lower cell's polarization and high capacity. Fig 9 shows the cycle capacity profile. It is seen that a drop of 7\% in capacity occurred after 400 cycles with few slow rate CCCV cycles which had over 97\% initial capacity received. Consequently, the optimized CCCV protocol charging condition for 60 mins permits an irreversible capacity loss of less than $3 \%$ after 400 cycles. This implies that there was no significant electrode and electrolyte degradation within the 60mins charging using the CCCV protocol and 90mins discharging for the 400 cycles.

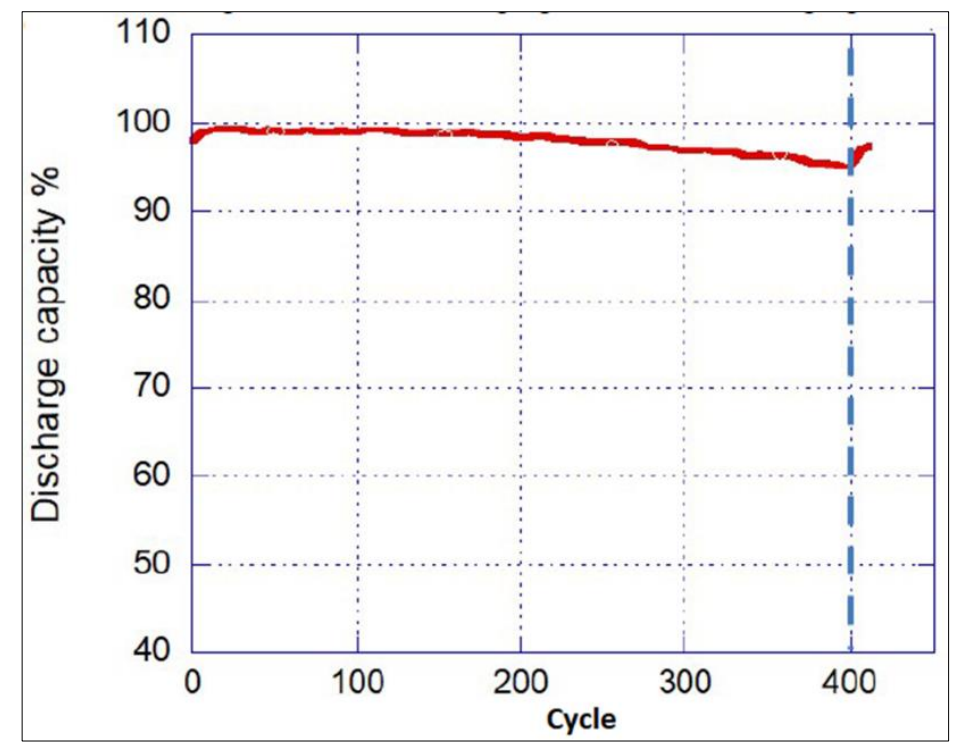

Figure 9 Discharge Capacity against Cycle Profile during CCCV Charge in 60mins for the first 400 Cycles 


\section{Conclusion}

Using proper C-rate and voltage restrictions throughout the CC and CV phases, an optimal CCCV technique with a controlled charging period of 60 minutes was obtained. In this specific situation the cells employed are based on the graphite/NMC chemistry and the most acceptable C-rate and voltage limit combination was achieved at $1.4 \mathrm{C}$-rate and $4.35 \mathrm{~V}$. After 400 cycles, $7 \%$ of the initial capacity was lost after $60 \mathrm{mins}$ CCCV charge at $0.6 \mathrm{C}$ discharge while $3 \%$ of initial capacity was lost after $300 \mathrm{~min}$ SCCV charge at same C-rate of $0.6 \mathrm{C}$. The ability to fully charge an LIB cell in $60 \mathrm{mins}$ while maintaining a high cycle capacity of 400 cycles is a significant improvement in lowering the charging time from the usual PED and BEV manufacturer's recommended charging time of $90-120$ mins. It is worthy to note that the optimized C-rate and $\mathrm{V}_{\text {lim }}$ combinations for $60 \mathrm{mins}$ full charge of cells depends on the cell's chemistry and design. To implement a 60 mins charge using the CCCV protocol, the best C-rate and $V_{\text {lim }}$ combination should be adapted. The CCCV protocol conditions are very much specific to the cell's chemistry and design.

\section{Compliance with ethical standards}

\section{Acknowledgments}

The Management and Staff of SHESTCO Abuja and Federal University Otuoke are greatly acknowledged for their support and creating the enabling environment in making this research possible.

\section{Disclosure of conflict of interest}

The authors declare that the research serves no personal or organizational interest. The authors declare no conflict of interest.

\section{References}

[1] Arumugam M, Xingwen Y, Shaofei W. Lithium Battery Chemistries Enabled by Solid-State Electrolytes. Nature Review Materials. 2017; 2(4): 1-14.

[2] Egor AO, Osang JE, Uquetan UI, Emeruwa C, Agbor ME. Inter-annual variability of rainfall in one state of southern Nigeria. International journal of scientific and technology research. 2015; 4(10): 1324-154.

[3] Emeruwa C, Abiodun IC. Effect of large scale use of compact fluorescent lamps in Nigerian electrical network. IOSR journal of electronics and communication engineering. 14(3, Ser 11): 22-30.

[4] Emeruwa C. Comparative analysis of signal strength of some cellular networks in umuahia eastern Nigeria. Journal of Electronics and communication engineering research. 2015; 2(10): 1-5.

[5] He H, Zhang X, Xiong R, Xu Y, Guo H. Online model-based estimation of state of charge and open-circuit voltage of lithium-ion batteries in electric vehicles. Energy. 2012.

[6] Johnson VH, Pesaran AA, Sack TNRE. Laboratory, and S. America, temperature-dependent battery models for high-power lithium-ion batteries: National Renewable Energy Laboratory. 2001.

[7] Junping W, Jingang G, Lei D. An adaptive Kalman filtering based state of charge combined estimator for electric vehicle battery pack. Energy Conv Manage. 2009; 50: 3182-6. 